\title{
Marco legal cultural de México
}

\section{Cultural legal framework of Mexico \\ Mateo Calderón-Sánchez ${ }^{a}$}

\begin{abstract}
:
The Mexican legislative framework on the laws that refer to the Culture and Cultural Heritage of Mexico in a direct and indirect way is poured into an axiology of remembrance and contemporary values, through this juxtaposition the need to link the relationship of objects is perceived of study with the subjects that consider patrimonial those relationships that build their patrimony; Furthermore, a restructuring of the institutions entrusted by the federal government with managing, preserving and conserving said heritage is required.
\end{abstract}

Keywords:

Laws, culture, cultural heritage, Mexico, object-subject

\section{Resumen:}

El marco legislativo mexicano sobre las leyes que se refieren a la Cultura y al Patrimonio Cultural de México de forma directa e indirecta se vierte en una axiología de valores rememorativos y de contemporaneidad, mediante esta yuxtaposición se percibe la necesidad de vincular la relación de los objetos de estudio con los sujetos que consideran patrimoniable aquellas relaciones que construyen su patrimonio; además hace falta una reestructuración de las instituciones encargadas por parte del gobierno federal de gestionar, preservar y conservar dicho patrimonio.

\section{Palabras Clave:}

Leyes, cultura, patrimonio cultural, México, objeto-sujeto

\section{Introducción}

Definir que es "patrimonio" puede ser simple si tomamos en cuenta que el concepto está ligado al de herencia, cuyas raíces latinas patr" es "padre" y monium, "recibido", es decir, lo que se deja a los descendientes. Sin embargo no necesariamente esto sucede con el concepto de "patrimonio cultural", ya que según el antropólogo Canclini (1999) afirma que dicha herencia no sólo lo incluye como el patrimonio de cada pueblo que agrega las expresiones y manifestaciones de sus necesidades contemporáneas, es decir, tanto lo material como lo inmaterial. De forma similar lo menciona la UNESCO (1972) al referirse simplemente al Patrimonio Cultural para diferenciarlo del Natural, lo define como los monumentos históricos, los conjuntos arquitectónicos, los sitios arqueológicos que mediante la materialidad resguarden el pasado; incluso da un paso más allá al agregar y/o clasificar el Patrimonio Cultural Inmaterial (2003) al que define como los usos, representaciones, expresiones, conocimientos y técnicas -junto con los instrumentos, objetos, artefactos, espacios culturales que les son inherentes- que las comunidades o ciertos grupos reconozcan como parte de su bagaje cultural, esto con la finalidad de distinguirlo del Patrimonio Cultural Material. Con base en estos preceptos se han decretado (o no) leyes en México para conservar y preservar el Patrimonio Cultural de la nación sin especificar dicho término en las mismas.

\section{Desarrollo}

El tratado del tema respecto al marco legal del Patrimonio Cultural de México es deficiente, o por lo menos se ha hecho de forma limitada y desde una esquina subjetiva como el caso de Cottom (2006) que hace una crítica

Autor de Correspondencia, Universidad Autónoma del Estado de Hidalgo, https://orcid.org/0000-0001-9468-0788, Email: mattheocalderony@gmail.com 
cómoda a la legislación mexicana pero desde su puesto de funcionario federal sin abordar más allá el tema ni priorizar el concepto de "patrimonio cultural", caso contrario que Chávez-Aguayo $(2015,2019)$ quien se atreve a hacer un análisis de dicho marco legal y la necesidad de abordar una perspectiva actual en la que se priorice la relación del objeto de estudio con lo sujetos.

Al leer y analizar las leyes mexicanas en el rubro de Patrimonio Cultural es notable deducir que el concepto de "Patrimonio Cultural" es nuevo como se muestra en la Ley General de Cultura y Derechos Culturales (2017) pero únicamente en el rubro de lo Intangible, no así en la Ley Federal sobre Monumentos y Zonas Arqueológicos, Artísticos e Históricos (1972) que medio siglo después sigue sin adecuarse a terminologías actuales y perspectivas que favorezcan la participación de grupos sociales que sean quienes actúen en pro de su propio patrimonio, del cual se encargan, según las leyes, el Instituto Nacional de Antropología e Historia (1939) y el Instituto Nacional de Bellas Artes y Literatura (1946) que en sus respectivas leyes se encargan de gestionar el patrimonio cultural material pero sin mencionar dicho término y lo hacen por criterios de periodos históricos dejando de lado otros como los estéticos, por ejemplo.

Esto nos lleva a reflexionar sobre el marco legal -conjunto de leyes referentes a- o propiamente dicho, la LEGISLACIÓN en materia de Cultura, Patrimonio Cultural y Derechos Culturales de nuestro país; para lo cual es necesario leerlas y estudiarlas; evaluar ¿cuál es la realidad actual de México respecto al cuidado de su patrimonio? ¿las comunidades, usuarios y beneficiarios se hacen cargo del mismo? ¿se les permite el acceso y se les otorgan herramientas que faciliten su gestión?

\section{Conclusión}

Es importante notar que contamos con una conjunto de leyes que intentan y procuran proteger los distintos tipos de patrimonio cultural: material, inmaterial; en otras están pendientes como el documental y el biocultural; sin embargo, a más de medio siglo de distancia del promulgación de la Ley Monumentos... es importante cuestionarnos su vigencia, o su actualización.

Es justo y necesario revisar las leyes, investigarlas y reformarlas, traducirlas, hacerlas accesibles; incorporar de facto y no en la teoría verdaderamente a la población. Aunque ciertamente existen ya leyes que se acercan al tratamiento del patrimonio cultural, ello nos llevará a más discusiones respecto al tratamiento legal de la Cultura y el Patrimonio Cultural, y eso es un pendiente que en la práctica las instituciones nos quedan a deber, sin embargo, es un inicio y estamos en el momento coyuntural en el que las condiciones político-sociales favorecen la oportunidad de traer la discusión a la mesa.

\section{Referencias}

[1] Chávez-Aguayo, Marco Antonio. Una mirada social sobre el concepto de patrimonio y su evolución. 2015.

[2] Chávez-Aguayo, Marco Antonio. Análisis de la Ley General de Cultura y Derechos Culturales en México. 2019.

[3] Cottom, Bolfy. La legislación del Patrimonio Cultural de interés nacional: entre la tradición y la globalización, análisis de una propuesta de ley. 2006.

[4] García-Canclini, Néstor. Los usos sociales del Patrimonio Cultural. 1999.

[5] Ley Federal sobre Monumentos y Zonas Arqueológicos, Artísticos e Históricos. 1972

[6] Ley General de Cultura y Derechos Culturales. 2017.

[7] Ley Orgánica del Instituto Nacional de Antropología e Historia. 1939.

[8] Ley que crea el Instituto Nacional de Bellas Artes y Literatura. 1946.

[9] UNESCO. Convención sobre la Protección del Patrimonio Mundial Cultural y Natural. 1972.

[10] UNESCO. Convención para la Salvaguardia del Patrimonio Cultural Inmaterial. 2003. 